\title{
O LIVRO DIDÁTICO E SUAS CONTRIBUIÇÕES PARA O ENSINO RELIGIOSO
}

\author{
THE DIDATHIC BOOK AND ITS CONTRIBUTIONS TO \\ RELIGIOUS EDUCATION
}

\author{
Maria da Penha Lima da Silva ${ }^{1}$ \\ Danielle Ventura de Lima Pinheiro ${ }^{\text {II }}$
}

\section{RESUMO}

O livro didático é uma importante ferramenta de trabalho utilizada pelos professores e manuseada diariamente pelos alunos. No caso do Ensino Religioso, este material didático vem sofrendo mudanças ao longo dos anos, pois sai, paulatinamente, de um caráter prosélito para uma leitura plural do fenômeno religioso, consequência de um esforço contínuo de instituições como o Fórum Nacional Permanente do Ensino Religioso (FONAPER), que vem dando um novo direcionamento para as abordagens que precisam ser desenvolvidas em sala de aula tomando como base os Parâmetros Curriculares Nacionais do Ensino Religioso (PCNER). Estudar o livro didático para o Ensino Religioso, atentando para suas peculiaridades, limitações e capacidade de incentivo à leitura é o objetivo deste trabalho. Para tanto, partiu-se de um estudo de autores que atentam para essas questões próprias deste recurso metodológico, como também se refletiu sobre as abordagens mais específicas, destinadas ao Ensino Religioso. De antemão, o estudo propiciou a apresentação tanto das especificidades do livro didático nesta área do conhecimento, suas utilizações nem sempre adequadas ao que o aluno precisa como também foi capaz de ressaltar os seus pontos positivos partindo, especialmente, da obra de Carniato (2009) como apta a atender ao que vem sendo refletido pelos profissionais da área sobre a proposta para o Ensino Religioso.

Palavras-chave: Ensino Religioso. Livro Didático. Leitura.

\section{ABSTRACT}

The textbook is an important work tool used by teachers and handled daily by students. In the case of Religious Education, this didactic material has undergone changes throughout the years, since it gradually leaves a proselytizing character for a plural reading of the religious phenomenon, the consequence of a continuous effort of institutions such as the Permanent National Forum of Religious Education ( FONAPER), which has been giving a new direction to the approaches that need to be developed in the classroom based on the National Curriculum Parameters of Religious Education (PCNER). Studying the didactic book for Religious Education, considering its peculiarities, limitations and ability to encourage reading is the objective of this work. To do so, we started with a study of authors that look at these specific questions of this methodological resource, but also reflected on the more specific approaches, aimed at Religious Education. The study provided a basis for the presentation of both the specificities of the textbook in this area of knowledge, its uses not always adequate to what the student needs, but also was able to highlight their positive points, starting from Carniato's (2009) as apt to attend to what has been reflected by the professionals of the area on the proposal for Religious Education.

Keywords: Religious education. Textbook. Reading.

Tniversidade Federal da Paraíba / UFPB- Brasil. E-mail: misspenha.rom@gmail.com

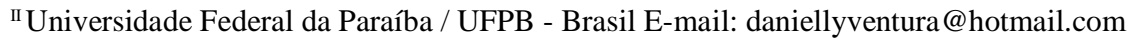




\section{INTRODUÇÃO}

As mudanças prementes aos livros didáticos do Ensino Religioso são fruto de um cenário educacional que vem se pautando no respeito à diversidade religiosa e na necessidade de compreender o fenômeno religioso em suas múltiplas dimensões. Logo, fazem parte de um debate promovido na atualidade pelas universidades e pelo FONAPER por incentivarem um estudo pautado naquilo que está previsto pela $\mathrm{LDB} / 96$ e pela $\mathrm{CF} / 88^{1}$.

Trazer este suporte metodológico à tona é enriquecer a discussão sobre o Ensino religioso tão presente em dissertações e teses brasileiras $^{2}$. Logo, permitirá uma abordagem diferenciada que vai além das mudanças na atualidade, mas pensa especificamente em como elas são capazes de repercutir diretamente no livro didático.

Presente diariamente na sala de aula, este material não pode ser ignorado, pois seu manuseamento eficaz garantirá o sucesso ou o fracasso de todo um trabalho a ser desenvolvido durante o ano letivo. De antemão, destacam-se aqui os prejuízos de seu mau uso e como a correlação deste material com outros recursos enriquecem o cotidiano escolar.

Enfim, pensar o livro didático oportunizará o conhecimento de como as mudanças do cenário brasileiro trazem repercussões na sua utilização e construção e, concomitantemente, como a sua utilização precisa ser refletida com cautela para se garantir o sucesso escolar a partir do incentivo à leitura.

\section{MATERIAL E MÉTODO}

O presente artigo adota como metodologia de estudo a revisão de literatura que inclui pesquisas já publicadas sobre o Ensino Religioso. Assim, partiu-se de um estudo de autores que discutem sobre o referido tema, problematizando sobre o Livro Didático como um dos recursos pedagógicos nessa área. Para estudar o livro didático como recurso metodológico discutiu-se sobre o sentido do termo "didático" e analisou-se a adequação do livro de Carniato (2009), considerando o que é proposto pelos Parâmetros Curriculares Nacionais do Ensino Religioso.

\section{RESULTADOS E DISCUSSÃO}

\section{As Mudanças dos Livros Didáticos do Ensino Religioso}

O livro didático pode ser considerado como uma fonte basilar de conhecimento sobre diversas culturas. Contudo, no caso específico do Ensino Religioso, percebe-se que, mediante

\footnotetext{
${ }^{1}$ Com a Lei de Diretrizes e Bases da Educação Nacional, (LDBEN) de $\mathrm{n}^{\circ}$ 9.394/96, cujo artigo 33 é modificado, dando origem, a Lei $\mathrm{n}^{\circ}$ 9.475/97 que afirma: Art. 33 - O ensino religioso, de matrícula facultativa, é parte integrante da formação básica do cidadão e constitui disciplina dos horários normais das escolas públicas de ensino fundamental, assegurado o respeito, à diversidade cultural religiosa do Brasil, vedadas quaisquer formas de
}

proselitismo. Além disso, o Artigo 5, inc.VI da $\mathrm{CF} / 88$ prevê como: [...] inviolável a liberdade de consciência e de crença, sendo assegurado o livre exercício dos cultos religiosos e garantida, na forma da lei, a proteção aos locais de culto e a suas liturgias.

${ }^{2}$ Dentre as dissertações e teses brasileiras aproximam-se desta temática: Brasileiro (2010), Abreu (2009) e Coelho (2009) 
uma herança colonial, alguns escritos ${ }^{3}$ eram voltados para uma só cultura. Sobre a postura da Igreja Católica frente ao Ensino Religioso tem-se a análise de Figueiredo (1995, p.96) que relata:

A partir dos anos 80, são inúmeros os pronunciamentos da Igreja Católica sobre Educação, Educação Religiosa e Ensino Religioso, quer em âmbito universal, quer em nível de Brasil. São tantas as orientações publicadas na forma de documentos eclesiais que merecem ser retomadas e analisadas em seus aspectos significativos.

É válido ressaltar que esses primeiros escritos estavam voltados para uma preocupação da Igreja Católica, direcionada para uma "tendência pedagógica" estruturada num princípio eclesial, objetivando uma proposta tecnicista, focada em textos cristãos. De fato, percebemos, no decorrer da história, que esses escritos sustentavam um Ensino Religioso confessional, tendo como objetivo maior a transmissão da religião cristã.

Atualmente, este quadro já se reverteu com o surgimento de novas propostas didático-pedagógicas, cujo suporte é o Livro Didático, que constitui material necessário para o processo de ensino e aprendizagem. Porém, não deve ser considerado como única fonte de conhecimento disponível para o educando, mesmo sendo utilizado didática e corretamente em sala de aula, pois o professor

\footnotetext{
3 São exemplos: "A descoberta do Reino de Deus" (elaborado pela Congregação Salesiana,); Coleção "Mundo Jovem" (elaborada pela equipe de Catequese das Edições Paulinas, anos 70); Coleção "Caminho" (Edições Loyola, formação cristã); Coleção "Meu Cristo Amigo" (Departamento de Catequese das Edições Paulinas); Coleção "Libertação Páscoa" (Secretariado Pastoral e Catequese de Santo Ângelo,
}

deve ter consciência da necessidade de um trabalho diversificado e, para tanto, é preciso buscar, em outras fontes, informações ou conteúdos que venham complementar e enriquecer o ensino e a aprendizagem. Sobre isso Miranda e Luca (2004, p.124) asseguram que:

Sendo este um produto cultural dotado de alto grau de complexidade e que não deve ser tomado unicamente em função do que contém sob o ponto de vista normativo, uma vez que não só sua produção vinculase a múltiplas possibilidades de do saber histórico, como também sua utilização pode ensejar práticas de leitura muito diversas.

A leitura é considerada uma atividade importante na educação. É um ato belo e único o momento que a criança aprende a ler. Esse é um dos objetivos mais relevantes da escola: Ensinar a ler e a escrever. Esses processos se iniciam quando o educando começa a manusear o seu livro didático, seus textos históricos ilustrados com suas belíssimas imagens, que chamam logo a atenção do aprendiz.

O livro didático poderá ser utilizado pelo o professor em situações de aprendizagem, partindo do princípio de manuseio, conhecimento e de atividades de leitura, com interpretações, reflexões sobre o que se lê, oportunizando o diálogo e fazendo com que as ideias vão surgindo, garantindo assim uma diversidade de saberes fundamentais na

editora vozes); Coleção "A escola em busca da Luz" (Secretariado Arquidiocesano de Pastoral. Editora, Vozes); outros textos didáticos para subsidiar os professores de ER: Coleção "Educação Nova" (Centro de Pedagogia Religiosa de Porto Alegre); Coleção "Educação Religiosa Escolar" (CIER - Santa Catarina) Coleção "Educação Religiosa de $1^{\circ}$ Grau" (CAER Porto Alegre - RS). (FIGUEIREDO, 1995, p. 97- 102). 
formação do educando.

[...] o livro didático se destina a promover interações entre o educador $\mathrm{e}$ o educando, oportunizando caminhos de acesso ao conhecimento sistematizado como auxiliar do trabalho docente em sala de aula. Desse modo, torna-se imprescindível entender que a educação além de valorizar o aspecto cognitivo do ser humano, contempla também o seu existir no conjunto de suas dimensões: física, afetiva, intelectual, religiosa e social (GOMES, 2010, p. 128).

Cabe ao educador estar também em sintonia com os alunos, despertando neles o interesse pela leitura com prazer, aplicando para isso dinâmicas diversificadas em sala de aula, já que o hábito de ler não é unânime entre todos os docentes. Assim,

Entendemos que o livro didático pode se apresentar como um estimulador para os docentes e discentes, incentivando para uma capacidade criadora, levando-os à descoberta de novos recursos, pois, ele, como um recurso de ensino aprendizagem, se porta possível de constantes complementações por se tratar de um instrumento que converge ao trabalho docente, visto que o uso do livro didático depende do trabalho que o educador se propõe a desenvolver, bem como, de sua visão de mundo (GOMES 2010, 129).

Por outro lado, consideramos que os livros didáticos disponibilizavam leituras cansativas, com textos longos e pouco atraentes para os alunos, sendo este um dos motivos pelos quais eles não desenvolviam o hábito de ler, tendo ainda a falta de incentivo por parte dos professores. Tal aspecto, pode se constituir como um dos entraves, que leva ao desestímulo das crianças, quando sentem dificuldades de ler.

Além disto, o livro quando é utilizado pelo professor como o elemento principal e único recurso do processo de ensino $\mathrm{e}$ aprendizagem pode se tornar pouco estimulante e perder sua função de recurso auxiliar da mediação do conhecimento. Freitag, Costa e Motta (1989, p.123-124) apontam pontos importantes sobre o livro didático e destacam que ele

[...] não é visto como um instrumento de trabalho auxiliar na sala de aula, mas sim como a autoridade, a última instância, o critério absoluto de verdade, o padrão de excelência a ser adotado na aula. Essa falta de crítica em relação ao livro didático vem acompanhada de uma visão estreita em relação ao que é útil necessário e recomendável para o aluno.

Assim, não se nega a contribuição do livro didático como um instrumento do ensino e aprendizagem, mas deve-se ter restrições ao seu uso como único responsável pelo aprendizado dos discentes. O aprendiz leitor, por sua vez, precisa da informação, do incentivo e dos desafios proporcionados pelo professor. Diante disso, partir-se-á, agora, para uma análise do livro didático como recurso metodológico.

\section{O Livro Didático como Recurso Metodológico: uma Experiência de Êxito?}

Para estudar o livro didático como recurso metodológico, pensamos primeiramente no sentido do que significa semanticamente o termo "didático", pois o consideramos como fundamental para que o livro utilizado em sala de aula atinja a sua real finalidade, que é a de garantir o aprendizado dos alunos. Em seguida, apontamos ainda a adequação do livro de Carniato (2009) ao que é 
proposto pelos Parâmetros Curriculares

Nacionais do Ensino Religioso, partindo de uma visão geral do livro didático em si para uma visão mais específica, o que nos leva a discutir sobre a realidade do Ensino Religioso atual adentrando a sala de aula a partir deste recurso metodológico.

Diante disso, sobre a didática, corrobora-se com Castro (2006, p.21), quando ele assegura que:

A importância da Didática tem uma determinada contribuição ao campo educacional, que nenhuma outra disciplina poderá cumprir. E nem a teoria social ou a econômica, nem a cibernética ou a tecnologia do ensino, nem a psicologia aplicada à educação atingem o seu núcleo central: o Ensino.

O autor destaca o caráter crucial da Didática, superando o lugar de vários campos educacionais. Entende-se aqui a educação como o ponto de abordagem maior da Didática. Logo, compreende-se que é na Didática que se devem estudar características e métodos de ensino que respeitem o desenvolvimento do homem, considerando seu processo histórico, social e cultural. Cabe ao educador estar atento às peculiaridades de cada aluno, procurando considerar sua bagagem cultural, respeitando suas limitações e seus conhecimentos prévios, independentemente de classe sociocultural e religiosa.

\section{A responsabilidade do professor é} intensa na questão didática e sua formação é o que garante, inclusive, o bom manuseamento do livro didático em sala de aula. É a sua formação que garantirá a existência de um ensino pleno capaz de envolver os discentes e de motivá-los à utilização do livro didático, pois a Didática

[...] oferece uma contribuição indispensável a formação dos professores, sintetizando no seu conteúdo a contribuição de conhecimentos de outras disciplinas que convergem para o esclarecimento dos fatores condicionantes do processo de instrução e ensino, intimamente vinculado com a educação e, ao mesmo tempo, provendo os conhecimentos específicos necessários para o exercício das tarefas docentes (LIBÂNEO, 2013, p.74).

Neste emaranhado de conhecimentos necessários ao professor para atuar em sala de aula, para melhor conduzir o aprendizado dos seus alunos, cumpre um papel especial o livro didático que seria, então, aquele livro que se adequa aos pressupostos da Didática, que contribui para que o conhecimento realmente ocorra. Porém, o livro didático não pode ser considerado como único recurso, mas precisa ser compreendido como aquele que tem uma linguagem adequada à realidade do discente e que está acessível ao aluno diariamente, não podendo ser desperdiçado.

O Livro Didático pode ser considerado como fundamental para todos os componentes curriculares, pois este é um excelente recurso metodológico que vai enriquecer o processo de ensino e aprendizagem. Por isso, Junqueira (2002, p.91) afirma que:

O livro didático do ER pode despertar o aluno para os aspectos transcendentes da existência como: a busca do sentido radical da vida, a descoberta de seu compromisso com o social e a conscientização de ser parte de um todo. Esse processo de despertar e descobrir, que é permeado de ações, gestos e 
palavras, símbolos e valores, que só adquirem significação na vivência, na participação e na partilha.

Os livros do Ensino Religioso da autora Carniato, possibilitam, no trabalho didáticopedagógico, a realização de técnicas atrativas, que apresentam uma diversidade de dinâmicas que vão despertar nos educandos uma maior participação nessa teia de saberes voltados para a diversidade cultural religiosa. Nos livros didáticos estão contidos os subsídios que vão ampliar o conhecimento da origem e da formação da ideia do transcendente na experiência humana. Segundo Carniato (2009, p.05):

A coleção de ensino religioso fundamental oferece: metodologia que favorece a observação do fenômeno religioso, a reflexão que leva a perceber pontos de unidade e de sentido nas várias tradições religiosas, a informação que possibilita a atitude de diálogo e reverência e a experiência que educa para atitudes conscientes e transformadoras.

Nesse caso verificamos que esta coleção está em consonância com os $\mathrm{PCNER}^{4}$, pois

\footnotetext{
${ }^{4}$ Os Parâmetros Curriculares Nacional do Ensino Religioso (PCNER) foi um documento elaborado com o objetivo de sustentar a substituição do artigo 33 da Lei de Diretrizes e Bases da Educação Nacional brasileira, que versa sobre o Ensino Religioso nas Escolas Públicas. Trata-se de uma proposta inovadora para o Ensino Religioso que tem como principal característica a mudança desse componente curricular do campo religioso para o campo secular.

5 O Fórum Nacional Permanente do Ensino Religioso (FONAPER) originou-se de algumas experiências de acolhimento e respeito entre igrejas cristãs que levaram, posteriormente, a repensar o Ensino Religioso com uma nova visão. Grupos de educadores, entidades religiosas, universidades e secretarias de educação, sentiam a necessidade de encaminhar uma nova forma de ministrar o Ensino Religioso, que acolhesse a diversidade cultural religiosa brasileira.

${ }^{6} \mathrm{O}$ Ensino Religioso conta com cinco eixos temáticos organizadores dos conteúdos: Culturas e Tradições

Religiosas: que contemplam aspectos do fenômeno
}

oferece uma proposta norteadora para $\mathrm{O}$

trabalho pedagógico do professor de Ensino Religioso nos moldes do FONAPER $^{5}$, envolvendo não só os docentes, mas também os discentes para busca da pesquisa aplicada às Ciências das Religiões.

As lendas também são apresentadas nas leituras da Obra de Carniato (2010, p. 10), pois se apresentam bem aplicadas quando se referem ao "Eixo Ethos dos povos e das culturas", fazendo abordagem sobre os costumes e valores dos povos e de suas religiões. Corroborando com a relevância deste estudo para área, Gomes (2010, p. 120) considera que esta atende ao objetivo de "despertar o educador do ER para a riqueza simbólica que estas lendas possuem, pois consideramos que as lendas transmitem e ensinam novas formas de comportamento, veiculando informações que são transmitidas de geração a geração" [...].

Nesse caso, destacamos a leitura como ponto fundamental para o crescimento sociocultural do educando. O professor é a

religioso, ou seja, função e valores das Tradições Religiosas, relação entre Tradição Religiosa e ética humana, existência histórica e destinação humana nas diferentes culturas etc. Textos Sagrados ou Tradições Orais: que transmitem as verdades de fé através das narrativas sagradas e seus contextos culturais, e as tradições orais que não possuem textos escritos, porém seguem as suas normas e preceitos éticos.; Teologias: estudo do conjunto de afirmações e conhecimentos elaborados sistematicamente pelas Tradições Religiosas, a respeito das divindades, fé, vida pós-morte, a realidade da existência humana, entendida como ressurreição, reencarnação, ancestralidade ou nada além da morte; Ritos: estudo das práticas celebrativas das Tradições Religiosas, com seus ritos, rituais, símbolos e suas espiritualidades; Ethos: Valor moral, formado pelo conjunto de valores que dão o sentido do viver humano e o princípio da alteridade sob a perspectiva religiosa propagada pelas tradições. FONAPER (PCNER 2002, p. 32-38). 
figura-chave no processo educacional, pois da imbricação de fatores que envolvem sua formação técnica profissional e dos saberes de sua vivência, tanto na profissão quanto na vida pessoal, dependerá significativa parcela do projeto educacional que compõe a realidade de nossas escolas.

Entendemos que o papel do professor assume uma importante responsabilidade quanto à sua formação, e que deve sempre exercer com eficácia e eficiência a sua tarefa de ensinar e educar. Uma realidade educacional de qualidade depende muito do envolvimento deste profissional. Neste sentido, não podemos deixar de refletir sobre os processos de formação e desenvolvimento profissional, destacando e desafiando novos caminhos e novos saberes para os educandos. Em face disto percebemos que Gomes (2010, p. 128) assevera ainda que: “[...] o livro didático se destina a promover interações entre o educador e oeducando, oportunizando caminhos de acesso ao conhecimento sistematizado como auxiliar do trabalho docente em sala de aula”. Enfim, é relevante o Ensino Religioso e o papel do professor ao utilizar o livro como uma ferramenta de maneira adequada, envolvendo seus alunos no uso e leitura crítica do mesmo, considerando a junção de outros conhecimentos e materiais, a fim de que ele consiga, de fato, aprender cada vez mais sobre a diversidade religiosa e respeite os diferentes credos existentes em sala de aula e fora dela.

\section{CONSIDERAÇÕES FINAIS}

É comum buscar compreender o Ensino Religioso a partir de pesquisa de campo ou de uma visão histórica que enfatiza o seu caráter prosélito e mudanças atuais. $\mathrm{O}$ diferencial deste estudo foi o de compreender e refletir o Ensino Religioso a partir do livro didático, recurso metodológico alvo de debates em diversos componentes curriculares.

Para além das mudanças de seus conteúdos, foi exposto aqui como o livro didático consegue trazer contribuições no aprendizado do aluno e a necessidade de se agregá-lo a outras leituras. Para tanto, é a formação do professor que fará com que ele tenha didática suficiente para conduzir a sala de aula de forma clara e atraente ao seu público.

Assim, ao se chamar atenção para o livro didático como recurso metodológico, damos a oportunidade de cada professor refletir sobre as suas práticas pedagógicas e de pensar como este recurso tem sido utilizado e como ele é capaz de proporcionar situações de aprendizado.

Enfim, este artigo aborda uma possibilidade de refletir sobre o papel do livro didático no contexto escolar, suas mudanças em consonância com a atualidade e as possibilidades de seu uso e a visão respeitosa para todas as religiões, respeitando aquilo que está disposto na LDB/96 e na CF/88.

\section{REFERÊNCIAS BIBLIOGRÁFICAS}

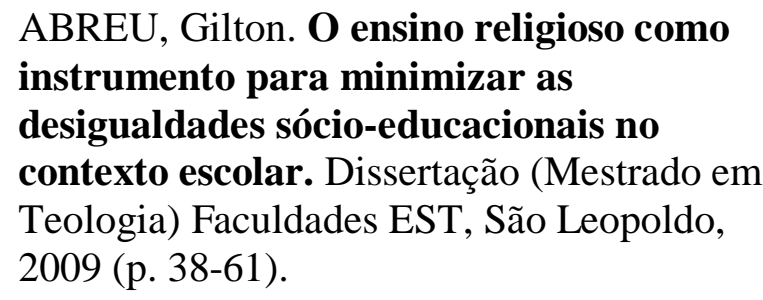

ABREU, Gilton. $O$ ensino religioso como instrumento para minimizar as desigualdades sócio-educacionais no contexto escolar. Dissertação (Mestrado em 2009 (p. 38-61). 
BRASILEIRO, Marislei de Sousa Espíndula. Ensino religioso na escola: o papel das ciências das religiões. Doutorado (Ciências da Religião). PUC-GO, GOIÂNIA, 2010.

CARNIATO, Maria Inês. A Religião no Mundo. Ed. Revista e Ampliada. $6^{\circ}$ ano Professor. Paulinas. 2009.

CASTRO, Amélia D. de. A Trajetória Histórica da Didática. Série Ideias, n.11. São Paulo: FDE, 1991 p.15-25. In <www.crmariocovas.sp.gov.br/amb $>>$.Acess ado em 20 de março de 2006.

COELHO, Maria Efigênia. Educação e Religião como elementos para a superação da Intolerância Religiosa. Integração e Relação na Compreensão do Ensino Religioso. Dissertação (Mestrado em Teologia), Faculdades EST, São Leopoldo, 2009.

FIGUEREDO, Anísia de Paulo. O Ensino Religioso no Brasil: tendências, conquistas, perspectivas. 2 edição. Petrópolis RJ: Vozes, 1996. (Coleção Ensino Religioso Escolar. Série Fundamentos).

Ensino Religioso: perspectivas pedagógicas. Petrópolis, RJ: Vozes. 1995. (Coleção ensino religioso escolar. Série fundamentos).

FREITAG, B.; COSTA, W. F.; MOTTA, V. R., O livro didático em questão. São Paulo: Cortez / Autores Associados, 1989.

GOMES, Eunice Simões Lins et al. As Lendas nos Livros Didáticos: uma análise mítica. (Orgs). FERREIRA, Santos Marcos. GOMES, Eunice Simões Lins. Educação \& Religiosidade: imaginários da diferença. Ed. Universitária UFPB. 2010.

JUNQUEIRA, Sergio. O processo de Escolarização do Ensino Religioso no Brasil. - Petrópolis, RJ: Vozes, 2002

LIBÂNEO, José Carlos. Didática. 2 ed. São Paulo: Cortez, 2013.

Como citar este artigo (Formato ABNT):

SILVA, Maria da Penha Lima da;
PINHEIRO,Danielle Ventura de Lima. O livro didático e suas contribuições para o ensino religioso. Educação, Psicologia e Interfaces, vol.1, n.1, p. 15-22, 2017. DOI: https://doi.org/10.37444/issn-2594-5343.v1i1.9

Recebido: 04/03/2017. Aceito: 05/04/2017. 